Ссылка: Бурденко Е.В. Рынок образовательных услуг в трансформируемой экономике: автореферат диссертации на соискание ученой степени кандидата экономических наук. - М.: ООО «МАКС Пресс», 2004. - с.22.

\title{
http://elibrary.ru/item.asp?id=24354757
}

\section{РЫНОК ОБРАЗОВАТЕЛЬНЫХ УСЛУГ В ТРАНСФОРМИРУЕМОЙ ЭКОНОМИКЕ: АВТОРЕФЕРАТ ДИССЕРТАЦИИ НА СОИСКАНИЕ УЧЕНОЙ СТЕПЕНИ КАНДИДАТА ЭКОНОМИЧЕСКИХ НАУК}

\author{
Бурденко Елена Викторовна - почетный работник высшего \\ профессионального образования, кандидат экономических наук, доцент \\ кафедры политической экономии Российского экономического \\ университета им. Г.В. Плеханова, \\ ResearcherID: E-3369-2014 \\ orcid.org/0000-0001-5073-5062 \\ burdenko-ev@yandex.ru
}

\section{Аннотация}

Диссертация состоит из введения, трех глав, содержащих 13 параграфов, заключения, библиографического списка использованной литературы, включающего 114 наименований, в том числе 9 на иностранном языке. Во введении обосновывается актуальность темы диссертационной работы, определяется степень разработанности проблемы, формулируется цель и задачи исследования, выделяются положения, выносимые на защиту, а также элементы научной новизны. В первой главе «Теоретикометодологические основы исследования образования в условиях формирования «экономики знаний» на основе системной и эволюционной парадигмы рассмотрено значение образования в формировании и повышении качества «человеческого капитала», проанализированы взгляды ученых на роль образования в развития общества. Во второй главе «Теоретические основы формирования рынка образовательных услуг» исследуются особенности производства, поведения потребителей и специфика поведения государства на рынке образовательных услуг в условиях трансформируемой экономики. В третьей главе «Новые явления в государственном регулировании рынка образовательных услуг» рассмотрены институциональные основы государственной политики и влияние интеграционных и глобализационных процессов на рынок образовательных услуг.

Ключевые слова: культура, наука. просвещение, образование, педагогические науки, народное образование, российская федерация, экономика народного образования, экономическая теория. 


\section{THE MARKET OF EDUCATIONAL SERVICES IN A TRANSFORMING ECONOMY: THE DISSERTATION ON COMPETITION OF A SCIENTIFIC DEGREE OF CANDIDATE OF ECONOMIC SCIENCES}

Burdenko, Elena V. - honorary worker of higher professional education, $\mathrm{PhD}$, Assistant Professor of the Department for Political Economy of the Plekhanov Russian University of Economics,

ResearcherID: E-3369-2014

orcid.org/0000-0001-5073-5062

burdenko-ev@yandex.ru

Abstract

The dissertation consists of introduction, three chapters, containing 13 sections, conclusion, bibliographical list of references that includes 114 titles, including 9 in a foreign language. In the introduction substantiates the relevance of the topic of the thesis is determined by the extent of the problem, formulates the goal and objectives of the study, highlighted the provisions submitted for protection, as well as elements of scientific novelty. In the first Chapter "Theoretical and methodological foundations of the study of education in the formation of a "knowledge economy" based on systematic and evolutionary paradigm considers the significance of education in shaping and improving the quality of human capital, analyzes the views of scientists on the role of education in development of society. In the second Chapter "Theoretical bases of formation of the market of educational services" peculiarities of production, consumer behavior and specific behavior of the state in the market of educational services in the conditions of transformed economy. In the third Chapter, "New developments in state regulation of the market of educational services" considers institutional foundations of public policy and the impact of integration and globalization processes on the market of educational services.

Keywords: culture, science. education, education, pedagogy, public education, the Russian Federation, economy of public education, economic theory. 
На правах рукописи

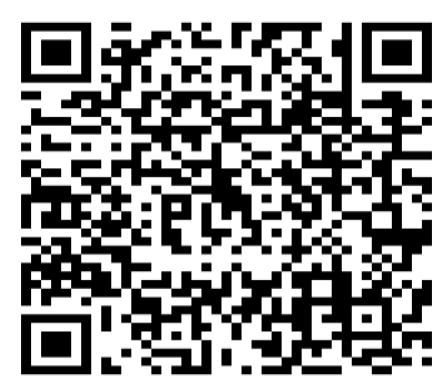

Бурденко Елена Викторовна

РЫНОК ОБРАЗОВАТЕЛЬНЫХ УСЛУГ В ТРАНСФОРМИРУЕМОЙ ЭКОНОМИКЕ

\author{
Специальность 08.00.01 - Экономическая теория \\ (область исследования: \\ Макроэкономическая теория)
}

\begin{abstract}
АВТОРЕФЕРАТ
диссертации на соискание ученой степени

кандидата экономических наук
\end{abstract}

Москва - 2004 
Работа выполнена в Российской экономической академии имени Г.В.Плеханова

Научный руководитель — _ _ _ доктор экономических наук, профессор Чередниченко Лариса Геннадиевна

Официальные оппоненты - доктор экономических наук, профессор Уколов Владимир Федорович кандидат экономических наук, доцент Гуськова Марина Федоровна

Ведущая организация $\quad-\quad$ Московский педагогический
государственный университет

Защита состоится « $11 »$ февраля 2005 года в 14.00 часов на заседании диссертационного совета Д 212.196.03 по экономическим наукам в Российской экономической академии им. Г.В. Плеханова по адресу: г. Москва, Стремянный пер., д. 36, 3 корп. 353 аудитория

С диссертацией можно ознакомиться в библиотеке Российской экономической академии им. Г.В. Плеханова.

Автореферат разослан «11» января 2005 года

Ученый секретарь

диссертационного совета,

к.э.н., доцент

Лисовская Е.Г. 


\section{ОБЩАЯ ХАРАКТЕРИСТИКА РАБОТЫ}

Актуальность темы исследования. Переход к рыночным отношениям и трансформация всей экономической системы России заставляют искать новые инновационные пути развития экономики и особенно рынка образовательных услуг. Перед экономической теорией, как научной дисциплиной, встает вопрос об исследовании значения образования в новых условиях, методах регулирования рынка образовательных услуг, его взаимосвязи с рынком труда и факторами, влияющими на формирование спроса и предложения на данном рынке.

Формирующийся современный рынок образовательных услуг обладает рядом особенностей, среди которых научный интерес представляет поведение потребителей и производителей образовательных услуг в условиях трансформируемой экономики. Особая роль на рынке образовательных услуг принадлежит государству, которое выступает как потребитель накопленных знаний и результатов образования и поэтому заинтересовано в контроле и регулировании рынка, и как опосредованный производитель через сеть образовательных учреждений, получающих бюджетное финансирование. Динамичное развитие экономики государства предъявляет новые требования к образованию: непрерывность образования, способность быстро адаптироваться к изменяющимся экономическим условиям и т.д.

В «Основных направлениях социально-экономической политики Правительства РФ на долгосрочную перспективу» говорится о возрастании роли человеческого капитала и образования как основного фактора его сохранения и развития. «Опора на образованность общества, на качество человеческого капитала, - отмечается в документе, - позволит России сохранить свое место в ряду государств, способных оказывать влияние на мировые процессы, ... ответить на вызовы, стоящие перед ней в 
социальной и экономической сферах, в обеспечении национальной безопасности и укреплении институтов государства» ${ }^{1}$.

Можно утверждать, что проблема формирования рынка образовательных услуг в современных условиях принадлежит к фундаментальным исследованиям и связана как с определением направлений развития всей системы образования, так и становлением взаимоотношений между всеми субъектами данного рынка, что зависит от степени влияния государства. Поэтому изучение, обобщение, обоснование и уточнение методологических подходов к проблеме формирования рынка образовательных услуг в условиях трансформации экономической системы являются актуальными и могут быть выдвинуты в разряд первоочередных задач в структуре социально-экономических исследований.

Степень научной разработанности проблемы. Исследованием увеличения стоимости человеческих ресурсов и эффективности труда в результате обучения занимались основатели классической политэкономии У. Петти, А. Смит, Д. Рикардо. Обосновали и развили теоретическую базу этого вопроса представители трудовой теории стоимости, и наиболее яркий её разработчик - К. Маркс. Особое внимание на вопрос образования обращали представители неоклассической теории Г. Беккер, Т. Шульц, Дж. Минсер и другие.

Оценка эффективности образования и факторов, влияющих на его состояние и развитие, анализируются в работах отечественных экономистов: С.Г. Струмилина, В.А. Жамина, С.Л. Костаняна, Б.С. Рябушкина, Ф.Ф.Стерликова и др. Проблемам сохранения и развития человеческого капитала посвящены работы отечественных ученых: В.С. Автономова, Г.П. Журавлевой, Р.И. Капелюшникова, В.И. Марцинкевича, Р.М. Нуреева, Б.В. Ракитского, В.Б. Супяна и др.

\footnotetext{
${ }^{1}$ Основные направления социально-экономической политики Правительства РФ на долгосрочную перспективу (извлечения) // Модернизация российского образования: документы и материалы / Ред. сост. Э.Д. Днепров. - М.: ГУ ВШЭ, 2002.-с.223.
} 
Теории трансформации экономических систем разрабатывались зарубежными и отечественными учеными: К. фон Бойме, Р. Дарендорф, Р.Даль, В. Меркель, К. Оффе, Ф. Рюб, В. Стеффани, Ф.Шмиттер, А.В. Бузгалин, Г.Ю.Ивлева, С.Н. Любимцева, Д.В. Миронов и др. Проблема формирования «экономики знаний» рассматривается в работах зарубежных и отечественных экономистов: Ф. Махлуп, Д. Тапскотт, М.Кастельс, К. Келли, Дж. Ходжсона, Г. Колодко, Л.И. Абалкина, А.А.Дынкина, В.Л. Макарова и др.

Проблемам функционирования и регулирования рынка образовательных услуг посвящены работы следующих экономистов: В.С.Баженова, Г. Вильямс, В.А. Герасимов, У.Г. Зиннуров, Ю.И. Иванов, Г.И. Лукьянова, В.Д. Остапченко, А.П. Панкрухин, Е.Н. Попов, Ф.М.Русинов, Н.А. Селезнова, А.И. Субетто, О.А. Хаширов и др.

Однако, проблема функционирования рынка образовательных услуг применительно к новым условиям - трансформации экономических систем - разработана недостаточно, чему и посвящено данное исследование.

Цель диссертационного исследования состоит в исследовании рынка образовательных услуг в условиях трансформации экономической системы, разработке методологических подходов к формирующимся рыночным отношениям в образовательной сфере, повышению роли образования в развитии человеческого капитала.

В соответствии с поставленной целью решались следующие задачи:

- дать характеристику образовательной услуги и формирующегося рынка образовательных услуг;

- выявить особенности рынка образовательных услуг в условиях трансформации экономической системы;

- рассмотреть цели и варианты поведения субъектов рынка образовательных услуг в новых условиях; 
- $\quad$ проанализировать влияние рынка труда на формирование спроса и предложения на современном рынке образовательных услуг, нового качества человеческого капитала, обусловленного формирующейся «экономикой знаний»;

- $\quad$ дать анализ институциональных основ государственной политики на рынке образовательных услуг в трансформируемой экономике;

- проанализировать интеграционные процессы на международном рынке образовательных услуг и их влияние на развитие российского рынка образовательных услуг;

- $\quad$ сформулировать перспективные направления развития современного рынка образовательных услуг на основе анализа рынка труда.

Предметом исследования является процесс формирования и функционирования рынка образовательных услуг в экономике России.

Объектом исследования выступает рынок образовательных услуг в трансформируемой экономике и его роль в формировании нового качества человеческого капитала.

Методологическую и теоретическую основу исследования составили труды классиков экономической теории, работы отечественных и зарубежных ученых по проблемам образования, оценки инвестиций в развитие человеческого капитала, по вопросам формирования «экономики знаний», теории трансформации и функционирования рынка образовательных услуг. В диссертации использовано сочетание макро- и микроэкономического анализа. В работе использованы диалектический и системный подходы, методы динамического, сравнительного анализа и синтеза.

Эмпирической основой исследования послужили законодательные и нормативные документы, регулирующие цели и задачи политики государства в сфере образования, статистические данные Госкомстата, 
публикации в периодической печати, монографическая и другая научная литература по теме исследования.

Научная новизна диссертационного исследования состоит в следующем:

- в процессе исследования теорий человеческого капитала, трансформации экономических систем, «экономики знаний» показано, что большая часть знаний является смешанным благом, поэтому измерение их ценности, исходя из затрат государства на науку, дает искаженную картину, то есть аргументирована необходимость научиться измерять спрос на знание и их предложение; проанализированы особенности образовательной услуги, которая является результатом хозяйственной деятельности производителя;

- раскрыта особенность формирования и функционирования рынка образовательных услуг в условиях развития «экономики знаний», которая сводится к образованию неразделимой триады рынков: рынка знаний, рынка услуг и рынка труда, которые нельзя рассматривать изолированно;

- в процессе анализа сделан вывод, что конкуренция на рынке образовательных услуг заключается в конкуренции качества и имиджа образовательной услуги и в целом близка к модели монополистической конкуренции; раскрыты особенности производства и потребления образовательных услуг, заключающиеся в неотделимости потребления образовательной услуги от её производства и неотделимости от её носителя; неисчерпаемость;

- на основе анализа методов ценообразования на образовательные услуги сделан вывод, что эффективнее синтезировать цену на основе комплексного сочетания методов: затратного, ориентируемого на потребителя, ориентируемого на конкурентов и ориентируемого на полезность образовательной услуги; 
- определены направления формирования институциональной основы развития рынка образовательных услуг, исходя из жестких отношений институтов для обеспечения общенациональных интересов;

- в процессе анализа раскрыты проблемы интеграции российского рынка образовательных услуг в международный рынок образовательных услуг, которые связаны с применением в европейских странах разных моделей образовательных стандартов.

Практическая значимость работы. Теоретические выводы и практический материал, содержащийся в диссертации, могут быть использованы в преподавании дисциплин «Экономическая теория», «Управление персоналом (человеческими ресурсами)», «Экономика образования», «Экономика и социология труда», а также использованы в практической деятельности.

Апробация работы. Основные результаты исследования содержатся в опубликованных научных работах и докладах на международных, межвузовских и вузовских конференциях.

По результатам диссертационного исследования опубликовано 12 научных работ общим объемом 4,8 п.л.

Структура и логика работы определены избранной темой, предметом и объектом исследования и отражают его цели и задачи. Диссертация состоит из введения, трех глав, содержащих 13 параграфов, заключения, библиографического списка использованной литературы, включающего 114 наименований, в том числе 9 на иностранном языке.

Во введении обосновывается актуальность темы диссертационной работы, определяется степень разработанности проблемы, формулируется цель и задачи исследования, выделяются положения, выносимые на защиту, а также элементы научной новизны. 
В первой главе «Теоретико-методологические основы исследования образования в условиях формирования «экономики знаний» на основе системной и эволюционной парадигмы рассмотрено значение образования в формировании и повышении качества «человеческого капитала», проанализированы взгляды ученых на роль образования в развития общества.

Проведенное исследование и анализ теорий человеческого капитала на возрастание ценности человека, обученного и образованного по сравнению с человеком, не обладающим таковыми знаниями, показали, что приобретенные человеком способности к труду следует рассматривать как капитал в его «человеческой» форме. При этом под человеческим капиталом следует понимать не только способность выполнять определенную работу, но и использовать приобретенные знания и навыки человека, которые создаются путем инвестирования времени и труда в образовательные услуги, влияющие на рост производства и дохода.

Дан анализ вещественного и человеческого капитала, которые имеют следующие различия: права собственности на человеческий капитал, т.е. на приобретенные навыки и способности работника, не могут быть переданы другому лицу; затраты на образовательные услуги, связанные с получением более высоких способностей, являются одним из важнейших благ для человека; величину и изменения человеческого капитала невозможно измерить с той же точностью, что и для оборудования.

Современная теория человеческого капитала отражает переориентацию экономической науки с проблем использования трудовых ресурсов на проблемы создания качественно новой рабочей силы в условиях постиндустриального общества, а применительно к развитию экономических систем - переориентацию с экономических показателей на социальные показатели. Сегодня возрастает роль рынка образовательных услуг, так как образовательный уровень населения предопределяет его 
способность использовать информацию и технологию для экономического развития и образовательные услуги представляют собой процесс и результат создания человеческого капитала.

При оценке эффективности образовательных услуг широко применяется метод вычисления нормы прибыли от образования, основанный на регрессивном анализе. Но получить денежную оценку инвестиций в человеческий капитал достаточно трудно, поэтому Дж. Минсер предложил временной эквивалент оценки инвестиций для образовательных услуг.

Использование теории человеческого капитала возможно в России как на Западе. Она используется в области технико-экономического обоснования направлений инвестиций, осуществляемых государством, компаниями и работниками, а также при подсчетах вклада в экономический рост образовательных услуг и оценке их эффективности. Это означает, что не экономике придается "человеческое измерение", а наоборот - к человеку применяется экономическое измерение.

Затраты на человеческий капитал становятся эффективными инвестициями и носят долговременный характер. Воспроизводственный оборот человеческого капитала в 5-6 раз превышает длительность оборота основного капитала. При этом ценность человеческого капитала с накоплением знаний, опыта с годами увеличивается. Отдача на вложения в человеческий капитал, определяемая сопоставлением дисконтируемых заработков за период деятельности с затратами на образовательные услуги, существенно превышает отдачу от вложений в основной капитал. Согласно имеющимся оценкам, в развитых странах $60 \%$ прироста национального дохода определяется приростом знаний и образованности общества. ${ }^{2}$

\footnotetext{
${ }^{2}$ Щетинин В.П. Человеческий капитал и неоднозначность его трактовки// Мировая экономика и международные отношения. 2001. №12, с. 44.
} 
В последней трети XX века в результате накопления знаний, разработки новых технологий и их широкого распространения началось формирование информационно-индустриального общества, приходящего на смену индустриальному. Оно основывается на развитии науки и эффективных технологий, новом качестве человеческого капитала, изменении социальной структуры общества, более высоком уровне управления, более рациональном использовании ресурсов, связанных с этими факторами новыми возможностями в производстве, потреблении и снижении удельных затрат ресурсов на выпуск продукции и услуг. В совокупности эти обстоятельства образуют новый синергетический эффект, обуславливающий формирование нового общества.

Данное диссертационное исследование посвящено рынку образовательных услуг в трансформируемой экономике, поэтому ограничимся рассмотрением трансформационных состояний с точки зрения теории переходной экономики и теории трансформации капитализма.

Экономическая система в состоянии трансформации приобретает особые свойства и закономерности функционирования. С точки зрения теории переходной экономики процесс трансформации рассматривался как неотъемлемая принадлежность любой развивающейся экономической системы. Адаптация к новым формирующимся условиям всех членов общества возможна только через приобретение новых навыков и знаний, что невозможно без переобучения и приводит к возрастающей роли образовательных услуг.

Теория трансформации капитализма имеет глубокие исторические корни и объединяет огромное количество концепций. В целом, прослеживается два основных направления в исследовании капиталистической трансформации: анализ внутрисистемных изменений, связанных с преодолением ограничений в развитии капитализма, с 
повышением его жизнеспособности; а также гипотезы о способах, путях и формах возникновения посткапиталистического общества. Последнее направление активизировалось в 70-80е гг. и в настоящее время получило широкое распространение в экономической мысли, что свидетельствует о качественных изменениях в современных рыночных системах.

Нарастания новой волны трансформаций, трактуемых как процесс перерастания в постиндустриальное, информационное общество, в экономику знаний, способствует превращению знаний в доминирующий peсурс, повышению роли личности в процессе производства и возрастанию роли образования. ${ }^{3}$ Её отличительной чертой является ускоренное развитие нематериальной сферы и нематериальной среды хозяйственной деятельности. Производство, распределение и использование знаний составляют основу экономики знаний (табл. 1).

Таблица 1

Характеристика экономики знаний ${ }^{4}$

\begin{tabular}{|c|c|}
\hline Отличительные признаки & Сетевая, глобальная \\
\hline Сырье & Информация (не исчезает, не отчуждается) \\
\hline Закономерности & $\begin{array}{ll}\checkmark & \text { Закон повышающейся отдачи вместо закона } \\
& \text { убывающей отдачи } \\
\checkmark & \text { Короткие инновационные и жизненные циклы } \\
& \text { продукции и услуг }\end{array}$ \\
\hline Инфраструктура & Интернет \\
\hline Финансовые институты & $\begin{array}{l}\text { Венчурные фонды, рынки ценных бумаг компаний } \\
\text { высоких технологий (NASDAQ, Wesday, Nouveau } \\
\text { Marche) }\end{array}$ \\
\hline Кредитные источники & $\begin{array}{l}\text { Пенсионные фонды, корпорации, индивидуальные } \\
\text { инвесторы, домашние хозяйства }\end{array}$ \\
\hline Институты & $\begin{array}{l}\text { Интеллектуальная собственность, динамичная } \\
\text { конкуренция, низкие барьеры входа на рынки }\end{array}$ \\
\hline
\end{tabular}

В применении к России, где исследования сектора знаний только начинаются, где они затруднены из-за сложностей периода трансформации экономики, ослабления системы государственной отчетности, могут

\footnotetext{
${ }^{3}$ Ивлева Г.Ю. Трансформация экономической системы: обзор концепций и контуры общей теории//Общество и экономика. 2003. №10.

${ }^{4}$ Дынкин А.А. Экономика знаний урок для России// Вестник РАН, т.73, №5, 2003.
} 
использоваться некорректные, несколько завышенные оценки. Сопоставление данных о затратах на входе сектора знаний в странах OECD и России для двух вариантов выбора отраслей (только высшее образование и все уровни образования) показывает, что относительно ВВП у нас выделяется в первом случае в 3 раза, а втором в 2,1 раза меньше ресурсов, чем в среднем в странах OECD. В сравнении с США, Швецией, Южной Кореей Россия проигрывает еще больше.

Однако, следует учитывать, что экономике, основанной на знаниях, соответствует иная социальная структура, в которой отсутствует разделение труда между производителями и потребителями знания при участии посредника. Возникает новая система, в которой потребитель знания участвует в его создании. Рынок продуктов (знаний) заменяется рынком услуг.

Таблица 2

Сопоставление компаний традиционной экономики и экономики знаний, $2001^{5}$

\begin{tabular}{|c|c|c|c|c|c|c|}
\hline Компании & $\begin{array}{c}\text { Физиче- } \\
\text { ские } \\
\text { активы, } \\
\text { млрд. } \\
\text { долл. }\end{array}$ & $\begin{array}{c}\text { Рыночная } \\
\text { капитали- } \\
\text { зация, } \\
\text { млрд. } \\
\text { долл. }\end{array}$ & $\begin{array}{c}\text { Коэффи- } \\
\text { циент } \\
\text { Тобина }\end{array}$ & $\begin{array}{c}\text { Числен- } \\
\text { ность } \\
\text { занятых, } \\
\text { тыс. чел. }\end{array}$ & $\begin{array}{c}\text { Затраты на } \\
\text { исследова- } \\
\text { ния и } \\
\text { разработки } \\
\text { к числу } \\
\text { занятых, } \\
\text { тыс. долл. }\end{array}$ & $\begin{array}{c}\text { Затраты на } \\
\text { исследова- } \\
\text { ния и } \\
\text { разработки } \\
\text { к объему } \\
\text { продаж, \%. }\end{array}$ \\
\hline \multicolumn{7}{|c|}{ Компании традиционной экономики } \\
\hline $\begin{array}{l}\text { Даймлер- } \\
\text { Крайслер }\end{array}$ & 372 & 46 & 0,12 & 441 & 14 & 2,9 \\
\hline $\begin{array}{l}\text { Дженерал } \\
\text { Моторс }\end{array}$ & 315 & 33,8 & 0,11 & 594 & 13,5 & 4,9 \\
\hline Форд & 284 & 28,7 & 0,1 & 345 & 17,4 & 4,1 \\
\hline Ниппон стил & 34 & 4,8 & 0,14 & 26,3 & 11,9 & 4 \\
\hline \multicolumn{7}{|c|}{ Компании экономики знаний } \\
\hline Майкрософт & 59,3 & 326,6 & 5,5 & 50,6 & 86,6 & 16,9 \\
\hline Интел & 44,4 & 203,8 & 4,6 & 80 & 36,8 & 9,4 \\
\hline Ай-Би-Эм & 88,3 & 179 & 2 & 319 & 16 & 5,5 \\
\hline Циско & 35,2 & 124 & 3,5 & 35 & 63,4 & 10,8 \\
\hline
\end{tabular}

\footnotetext{
${ }^{5}$ Дынкин А.А. Экономика знаний урок для России// Вестник РАН, т.73, №5, 2003.
} 
Доля стоимости знания увеличивается и в национальном продукте за счет роста вклада секторов, связанных с производством и управлением знанием: научные исследования, образовательные, финансовые, страховые и деловые услуги, консалтинг. Экономические параметры компаний экономики знаний существенно отличаются от характеристик традиционных фирм (табл. 2).

Образовательные услуги как объект рынка образовательных услуг имеют определенную специфику. Они относятся к благам, обладающим особыми достоинствами: социальной защиты, так как образование сейчас способствует защите населения от безработицы; социальной мобильности, так как возросла социальная ценность образования, как важного канала перемещения в обществе, который повышает вертикальную социальную мобильность; адаптации, т.е. приближения молодежи к международным рынкам высококвалифицированного труда.

Образовательные услуги, являясь исключаемым смешанным благом, сочетают в себе черты чистого общественного и чистого частного блага. Образовательная услуга как товар - это полезный вид труда, непосредственно удовлетворяющий потребность человека в образовании, и как материально - вещественные продукты, позволяющие удовлетворять образовательную потребность человеком самостоятельно (учебники, обучающие программы, пособие и т.п.).

Обобщая все выше сказанное, дано следующее определение рынка образовательных услуг. Рынок образовательных услуг - это конкурентная связь, возникающая на основе прозьюментного взаимодействия субъектов в результате купли-продажи образовательных услуг и функционирующая в рамках государственного регулирования.

Человеческий капитал, как сумма врожденных способностей, общего и специального образования, приобретенного профессионального опыта, творческого потенциала, морально-психологического и физического 
здоровья, мотивов деятельности, обеспечивающих возможность приносить доход - все в большей мере определяет экономическое развитие. В этих условиях возрастает роль рынка образовательных услуг, который является механизмом превращения знаний в товар.

Во второй главе «Теоретические основы формирования рынка образовательных услуг» исследуются особенности производства, поведения потребителей и специфика поведения государства на рынке образовательных услуг в условиях трансформируемой экономики.

Характерной чертой рынка образовательных услуг в трансформируемой экономике является то, что предметом предложения выступает не сама образовательная услуга, а её результат, воспринимаемый каждым субъектом отношений в контексте сложившихся у него представлений о ценности образовательной услуги. Со стороны человека знаком ценности образовательной услуги служит сертификат об образовании.

Производство образовательных услуг есть потребление довольно специфических (в отличие от продукта в форме товара) ресурсов. В основе производства образовательных услуг лежат знания (иногда - идеи). В роли субъектов рынка образовательных услуг, формирующих предложение, выступают образовательные учреждения всех уровней и индивидуальные производители. В функции производителей образовательных услуг входят: производство образовательных услуг в форме необходимых знаний, умений и навыков: по содержанию, объему, ассортименту и качеству; производство и оказание сопутствующих образовательных услуг в виде материально-вещественных продуктов.

Ценообразование на рынке образовательных услуг должно базироваться на накопленном опыте установления цены на товары и услуги. В настоящее время производителями образовательных услуг используются все основные методы ценообразования: затратные, 
ориентированные на потребителя, на конкурентов, на полезность образовательной услуги. Автономное использование какого-либо одного метода ценообразования представляется неплодотворным. Эффективнее синтезировать цену на основе комплексного сочетания методов.

Применительно к образовательным услугам существуют три основных типа потребителей: индивидуальные, предприятия и организации, общество в целом. В диссертации рассмотрены интересы каждой из групп. Оценка потребительского поведения проведена с использованием теории предельной полезности, теории эластичности потребления и спроса.

Покупая образовательную услугу, потребитель повышает стоимость своего товара - «рабочей силы» на рынке труда. Степень полезности образовательной услуги индивидуальный потребитель определяет эмпирически, так как ожидаемый потребительский эффект образует сложный комплекс (будущее место работы, уровень дохода, возможность самореализации и т.д.). По мере повышения благосостояния потребителей на рынке образовательных услуг начинают котироваться программы послевузовского образования: профессиональной переподготовки, аспирантские, докторские.

С развитием рыночных отношений меняется отношение к рынку образовательных услуг как государства, так и населения, что заставляет рассмотреть особенности производства и потребления образовательных услуг: совмещением момента производства и потребления; неотделимостью образовательной услуги как от производителя (учебного учреждения), так и от потребителя, окончившего определенный вуз и получившего квалификацию; отсутствие возможности складирования и транспортирования образовательной услуги отдельно от носителей этих знаний; неисчерпаемостью, так как всякое новое знание порождает потребность в ещё больших знаниях. 
Но, несмотря на перечисленные особенности образовательной услуги, на рынке образовательных услуг действуют такие экономические законы рынка, как изменения предложения, падающего спроса, конкуренции, ценообразования и др.

Для исследования спроса рынка труда на специалистов определенной квалификации было проведено исследование и анализ по следующим параметрам: 1) динамика вакансий кадровых агентств по различным специальностям; 2) размер заработной платы, предлагаемой работодателями для различных групп специалистов.

Как показывает анализ статистических данных, на протяжении последних лет наиболее востребованы на рынке труда такие специалисты, как менеджер по продажам, технолог производства, инженер торгового оборудования. Работодатели стали предъявлять более жесткие требования к персоналу: знание разных компьютерных программ, международных стандартов, иностранных языков.

Все происходящие изменения вызывают колебания на рынке труда и, как следствие, на рынке образовательных услуг. Спрос на образовательные услуги является вторичным по отношению к спросу на специалистов определенной квалификации. В целом рынок образовательных услуг обладает неоднородностью, которая обусловлена множеством сегментных и взаимосвязанных рынков, поэтому регулирование рынка образовательных услуг необходимо дополнять инструментарием государственного регулирования.

В третьей главе «Новые явления в государственном регулировании рынка образовательных услуг» рассмотрены институциональные основы государственной политики и влияние интеграционных и глобализационных процессов на рынок образовательных услуг.

В диссертационном исследовании проанализированы основные положения Концепции модернизации российского образования на период 
до 2010 года, приведены примеры управления, повышения конкурентоспособности вузов и повышения квалификации преподавателей в зарубежных странах. В целом, стратегия правительства нацелена на бюджетную экономию за счет переключения расходов на образовательные услуги на семейный бюджет в течение следующих десятилетий. Сейчас, как считают федеральные органы управления, 25 - 30\% семей могли бы финансировать образование детей. К 2010 г. их доля возрастет до $40-45 \%$. К этому времени намечается рост семейных расходов на образовательные услуги в 2 - 3 раза (в реальном исчислении).

Соотношение государственных и частных расходов на образовательные услуги в 2000 г. составляло: для общего среднего образования - 94 и 6\%; для высшего - 54 и 46\%. В среднем это соотношение оказалось равным 84 и 16\%, а на 2010 г. намечается 60 и $40 \% .^{6}$ Но в развитых странах оно должно быть иным, так как в условиях «экономики знаний» глобальное обновление научно-технического и образовательного потенциалов, приведение их структуры в соответствие с потребностями будущего по силам лишь государству.

Рассмотрен механизм государственного регулирования рынка образовательных услуг через систему финансирования. Одним из методов регулирования могут быть субсидии, влияние которых на распределение и обмен образовательными услугами проиллюстрировано выгодами перелива капитала. Проведено исследование поведения государства с точки зрения теории общественного выбора. Решение проблем принятия государством неэффективных с точки зрения общества законов и неэффективное управление со стороны бюрократии представители теории общественного выбора видят во всемерном ограничении экономических функций государства.

\footnotetext{
${ }^{6}$ Проблемы прогнозирования. 2002. №4. с. 131.
} 
Во второй половине XX века в развитии стран наиболее сильно проявилась тенденция к экономической интеграции. При создании рынка рабочей силы, качество которой зависит от уровня предоставляемых образовательных услуг, обнаружились не только положительные результаты, но и определенные трудности, обусловленные разностью подходов к организации образовательных услуг. Международный рынок образовательных услуг, где конкурируют системы стран Европейского Содружества, США, Японии, Австралии, уже сложился, и вписаться в него странам Центральной и Восточной Европы с их национальными системами профессионального образования, стандартами, классификаторами профессий крайне сложно.

В европейских странах наибольшее распространение получили следующие модели образовательных стандартов: экзаменационная, профессиональная, модульная или их комбинация. Уже сейчас на уровне государства желательно разработать проект государственных мероприятий, направленных на создание системы взаимоувязки (перехода) отечественных образовательных стандартов с международными стандартами профессионального образования, использовать опыт различных моделей.

Примерами согласования и сотрудничества между национальными системами образования и обучения в рамках общего европейского пространства являются Болонский процесс в области высшего образования и Брюгге-Копенгагенский процесс в области профессионального образования и обучения. Оба эти процесса направлены на создание к 2010 году европейской системы высшего и профессионального образования с тем, чтобы граждане Европы могли свободно выбирать любое высшее учебное заведение, работу, отрасль бизнеса и страну. Одной из практических задач Коллективной стратегии ЕС является интеграция 
России в общее европейское экономическое и социальное пространство и тесное сотрудничество в таких областях, как образование.

России еще только предстоит подключится к процессу Европейской и мировой интеграции образовательных услуг. Подписание Болонской декларации и приведение внутренних образовательных стандартов в соответствие $\mathrm{c}$ требованиями Европейского фонда образования позволят выйти российским вузам на международный рынок образовательных услуг. Взаимопризнание дипломов дает возможность отечественным вузам в большем объеме предоставлять образовательные услуги иностранным студентам, открывать свои филиалы в других странах, а выпускникам вузов быть более конкурентоспособными на международном рынке труда.

Тенденции развития рынка образовательных услуг в Европе и в мире оказывают воздействие на российский рынок образовательных услуг. Уже в настоящее время можно предположить, что те вузы, которые обладают такими преимуществами, как: развитая сеть филиалов в России; система дистанционного обучения на основе Интернет - технологий; совместные программы с зарубежными вузами; высококвалифицированный профессорско-преподавательский состав; современные методы и интерактивные технологии обучения; гибкая организационная структура - смогут быстрее всего встроиться в глобальный рынок образовательных услуг.

В заключении изложены основные выводы, сделанные в результате проведенного исследования формирования и функционирования рынка образовательных услуг в трансформируемой экономике.

\section{По теме диссертации опубликованы следующие работы:}

1. Бурденко Е.В. Развитие СЭЗ на юге Дальнего Востока // Четырнадцатые Международные Плехановские чтения. Тезисы 
докладов профессорско-преподавательского состава. - М.: Изд-во Рос. экон. акад., 2001.- 0,1 п.л.

2. Бурденко Е.В., Алиматов Д.Г. Образование и развитие человеческого капитала - главные факторы экономического развития // Межвузовский сборник научных трудов, вып.№3. - М.: Изд. МГУДТ, 2002.- 0,5 п.л.

3. Бурденко Е.В. Анализ рынка образовательных услуг // Материалы научно-практической конференции «Васильевские чтения: национальные традиции в торговле, экономике, политике и культуре».М.: Изд-во РГТЭУ, 2002.-0,1 п.л.

4. Бурденко Е.В. Институциональные основы государственной политики на рынке образовательных услуг. М.: Изд. МГУДТ, 2002. - 0,8 п.л.

5. Бурденко Е.В. Проблемы рынка образовательных услуг на современном этапе развития экономики России // Шестнадцатые международные Плехановские чтения. Тезисы докладов профессорскопреподавательского состава. - М.: Изд-во Рос. экон. акад., 2003.-0,1 п.л.

6. Бурденко Е.В. Интернет в бизнес - образовании // «Ученые записки»: Тамбовское региональное отделение вольного экономического общества России. т.5, вып.2, Тамбов, 2003. - 0,3 п.л.

7. Бурденко Е.В. Взаимосвязь рынка труда и рынка образовательных услуг // Вестник Московского государственного университета дизайна и технологии. Выпуск № 1 (43).- М.: ИИЦ МГУДТ, 2003.- 0,6 п.л.

8. Бурденко Е.В. Экономические субъекты рынка образовательных услуг // Семнадцатые Международные Плехановские чтения. Тезисы докладов профессорско-преподавательского состава.-М.: Изд-во Рос. экон. акад., 2004.-0,1 п.л.

9. Бурденко Е.В. Система международных образовательных стандартов и интеграция России в Европейское сообщество // «Наука и образование. Новые технологии». Межвузовский сборник научных трудов, вып.№1. - М.: Изд. МГУДТ, 2004. - 0,8 п.л. 
10. Бурденко Е.В. Преподавание экономической теории в условиях трансформации экономики // Актуальные проблемы преподавания экономической теории: Тезисы всероссийской научно-практической конференции. - М. - 2004 г. - 0,2 п.л.

11. Бурденко Е.В., Герасимова Н.В. Формирование инвестиционного спроса в современной России // «Наука и образование. Новые технологии». Межвузовский сборник научных трудов, вып.№3. М.: Изд. МГУДТ, 2004. - 0,7 п.л.

12. Бурденко Е.В. Экономические субъекты и поведение государства на рынке образовательных услуг // «Наука и образование. Новые технологии». Межвузовский сборник научных трудов, вып.№5. М.: Изд. МГУДТ, 2004. - 0,6 п.л. 
Напечатано с готового оригинал-макета

Издательство ООО «МАКС Пресс»

Лицензия ИД № 00510 от 01.12.99 г.

Подписано к печати 30.12.2004 г.

Формат 60х90 1/16. Усл.печ.л. 1,5. Тираж 100 экз. Заказ 1263.

Тел. 939-3890. тел./факс 939-38-91.

119992, ГСП-2, Москва, Ленинские горы, МГУ им. М.В. Ломоносова, 2-й учебный корпус, 627 к. 